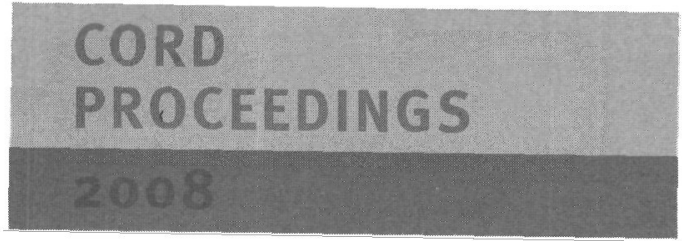

https://doi.org/10.1017/S2049125500000418 Published online by Cambridge University Press 


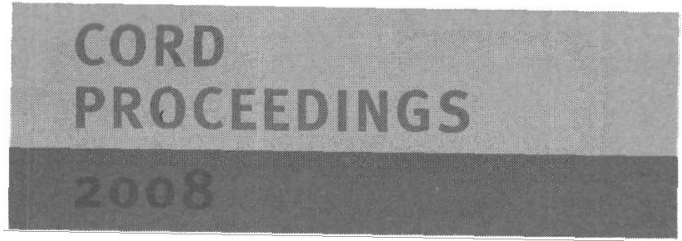

https://doi.org/10.1017/S2049125500000418 Published online by Cambridge University Press 
PRESIDENT: Barbara Sellers-Young

PAST-PRESIDENT: Ray Miller

Recording Secretary: Candace Feck

Treasurer: Carla Huntington

EDITORIAL BOARd CHAIR: Michael Huxley

\section{BOARD OF DIRECTORS}

Russ Patrick Alcedo

Ananya Chatterjea

Maura Keefe

Hari Krishnan

SanSan Kwan

Frederick John Lamp

Juliet McMains

Norton Owen

Claire Rousier

Karen Schaffman

Karen Vedel

Graduate Student Representative: Clare Croft

\section{EDITORIAL BOARD}

Mark Franko, Dance Research Journal Editor

Rebekah Kowal, Dance Research Journal Book Reviews Editor

Tresa Randall, Proceedings Editor

Ann Dils

Tricia Henry Young

OFFICE ADMINISTRATOR

Ashanti Pretlow, Prime Management Systems Executive Director

NATIONAL OFFICE

All inquiries regarding membership, publications, and future conferences should be directed to:

Congress on Research in Dance

34I 6 Primm Lane

Birmingham, AL 35216

Phone: (205) 823-5517

Fax: (205) 823-2760

Email: cord@primemanagement.net

Website: www.CORDance.org 


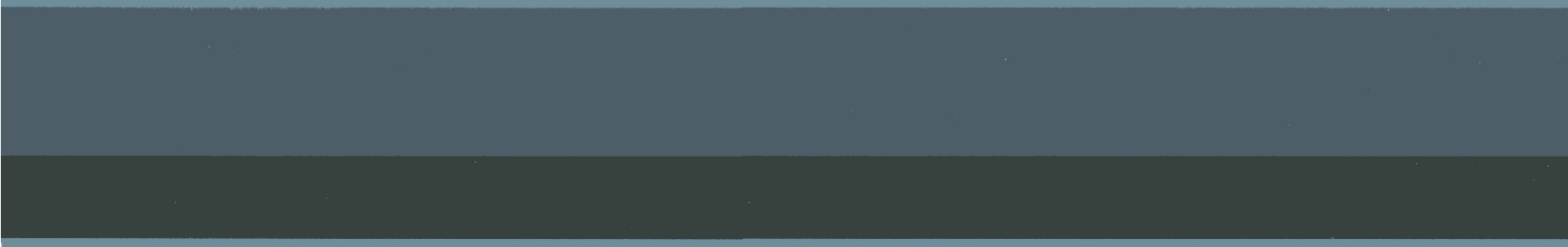

